\title{
DEVELOPING AN INFLATABLE SOLAR ARRAY
}

\author{
Patrick K. Malone, L'Garde, Inc. \\ 15181 Woodlawn Ave., Tustin, CA 92680 \\ $714-259-0771$
}

\author{
Larry Crawford, USAF Phillips Laboratory/VTPN \\ Kirtland AFB, NM 87117 \\ $505-846-5754$
}

\author{
Geoffrey T. Williams, L'Garde, Inc. \\ 15181 Hoodlawn Ave., Tustin, CA 92680 \\ $714-259-0771$
}

\begin{abstract}
L'Garde is developing a light weight deployable solar array wing in the 200-1000 watt range, on the Inflatable Torus Solar Array Technology Demonstration (ITSAT Demo) Project. The power density goal is $90-100 \mathrm{~W} / \mathrm{Kg}$ for a $200 \mathrm{~W}$ wing. including structure and deployment mechanisms. In Phase 1, a proof of concept torus and array was constructed and deployed in the laboratory. A revised Phase 2 Torus and Array are now being fabricated. Phase 3 will be a space flight test.

The current design uses crystalline Si cells on an $A O$ protected flexible Kapton film substrate folded accordion style for stowage. The support structure is a rectangular frame comprised of two inflated cylinders, the array stowage box and $i$ ts cover. The cylinders, flattened, folded and stored for launch, are deployed by inflating with $\mathrm{N}_{2}$ and rigidized by straining the cylinder laminate material controllably beyond the elastic limit.
\end{abstract}

This array is designed for optimum power density but, due to availability, some of the components come from excess production runs. Because of this, the actual power density of the engineering prototype will be about $15 \%$ less than the baseline program array. which uses $2.2 \mathrm{mil}$ crystalline silicon cells, 4 " diameter inflatable tubes, and a $4: 1$ aspect ratio.

This project is funded by ARPA with technical management oversight by the Phillips Laboratory.

\subsection{Introduction}

In today's small satellite environment, low cost and high performance determine project success. As such, it is essential to maintain high reliability. low cost. and high efficiency satellite subsystems. The inflatable Torus Solar Array Technology (ITSAT) accomplishes this by having high power densities and minimal packaging volume at low cost. ITSAT offers an additional advantage in allowing a variety of photovoltaic media to be used.
The ITSAT program is comprised of three Phases. Phase 1 was a feasibility study of point designs for LEO, GEO and Molniya orbits with array sizes from 100 watts to several thousand watts. A prototype system was built and this phase was completed in October of 1991 . Phase 2 which is now in progress updates the final design of Phase 1. generates detailed drawings and produces a qualification flight unit. Phase 3 will refurbish the phase 2 qualification unit for flight and integrate it with a sponsored spacecraft that will fly it.

The ITSAT system will be qualified for space use under the one-of-a-kind requirements outlined in MIL-HDBK-343. The system will be refurbished as required to minimize risks during the Phase 3 effort.

\subsection{Solar Array Current State-of-the-Art}

The Defense Advanced Research Projects Agency (DARPA) Advanced Space Technology Program (ASTP) is defining, developing, and demonstrating high-payoff technology applications to improve space system operational support to various military and cormercial disciplines.

Under the ASTP effort, a number of small satellites are being designed. These satellites. typically with a mass of a few hundred kilograms or less, have stowed volumes that are less than a cubic meter, and require electrical power levels ranging from a few watts up to several kilowatts. Body mounted solar cells can meet some of the lower power requirements. For power levels above about 100 watts, deployable solar arrays are needed. Current solar array designs for more than 100 watts may exceed mass and volume restrictions both of which are critical.

To meet the solar array requirements of these smallsats, it was clear a new and unique approach was required; one that would involve thin flexible structures and thin flexible solar arrays. 
Spacecraft performance has always been constrained by power availability. Designers have limited their designs to match the power they could supply to the load. This is true for large and small satellites, but this project is directed toward developing power for small satellites. Figure 1.2-1 presents future US photovotaic space power needs. This paper concentrates on space power requi rements of $0.01 \mathrm{KW}$ to $1.0 \mathrm{Kw}$ though the ITSAT can be extrapolated to larger systems.

\begin{tabular}{lcc} 
Name & Weight, Ka. & $\begin{array}{c}\text { On-orbit Avg Power } \\
\text { Natts }\end{array}$ \\
\cline { 2 - 3 } MACSAT & 68 & 8.5 \\
MICROSAT & 23 & 6.0 \\
GLOMR & 68 & 4.3 \\
ISES & 82 & $9-15$ \\
STACKSAT & 68 & $7-12$ \\
STEP - 0 & & 160 Experiments \\
STEP - & & 90 Spacecraft \\
& & 52 Experiments \\
& & 43 Spacecraft
\end{tabular}

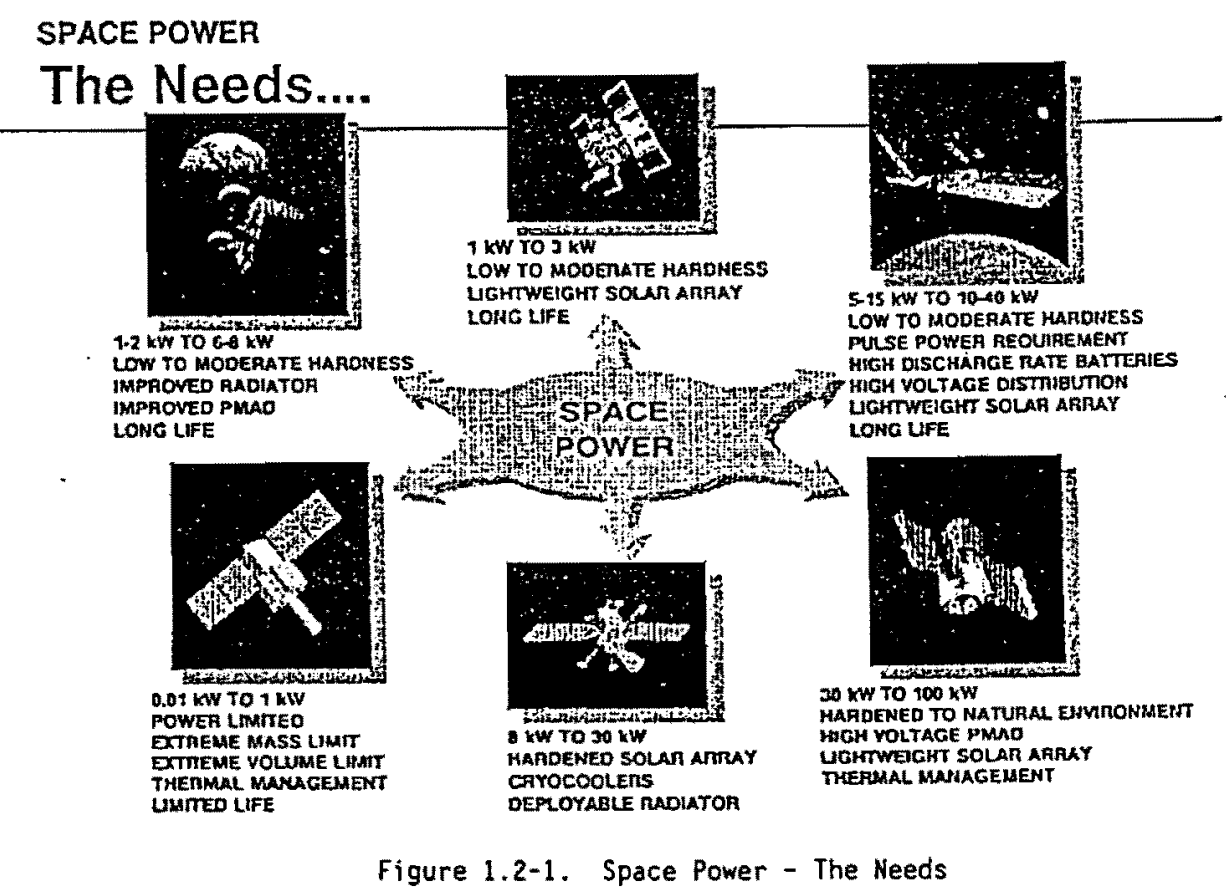

Demand for solar arrays of the type being developed in this project increase with the increasing production and use of small satellites. There is a widespread interest in small satellites and the speed of introduction will depend on US and world economy, world politics, and on the international allocation of radio frequency spectrum and approvals by the US FCC. Both military and civilian applications are being proposed.

Opposing views exist as to whether a sophisticated large satellite or numbers of small satellites are more economical and more effective in accomplishing the desired mission. The redundancy factor, for both civilian and military applications, appears attractive for small satellites where several may accomplish the task of one large satellite. Small satellites are also attractive from the ability to be launched more quickly (fewer delays), and from a total cost viewpoint.

\section{Military Applications:}

The Gulf War showed field commanders the utility of comunications by satellite, and the advantage of satellite navigation systems for ground position determination. Both are in demand. Small satellites for both applications may be more cost-effective than large satellites.

\section{Civilian Applications:}

Comunications and environmental monitoring are the principal civil applications for small satellites.

The numbers of small satellites required for environmental monitoring is likely to be moderate. Third world nations are interested because they have less access to Landsat and other similar satellite services. However, continuous coverage is not needed as in communications, and the need can be met with fewer spacecraft.

A large demand appears to be developing for small satellites for comunications, particularly for world-wide cellular telephone service, and for data transmittal service. The proposals include:

\begin{tabular}{|c|c|}
\hline Motorola & $\begin{array}{l}\text { Iridium (Voice) } \\
66 \text { Satellites }\end{array}$ \\
\hline Loral-Qualcom & $\begin{array}{l}\text { Globalstar (Voice) } \\
48 \text { Satellites }\end{array}$ \\
\hline $\begin{array}{l}3 \text { other voice and } \\
\text { data services }\end{array}$ & 145 Satellites \\
\hline
\end{tabular}

If approved by the FCC and launched on schedule, these satellites will all be in use by 1997. 
There has been some dissatisfaction with the cost and delays in launching large science satellites. This has led to proposals for launching a larger number of small less expensive satellites for science missions.

A small satellite requiring up to 100 watts can use body mounted PV cells. From 100 to about 350 watts, deployed but non-articulating panels or wings can be used. Above about 350 watts. articulated panels are preferred. The controlling factors in the choice are the mass and the stowed volume.

When using the DELTA II or larger launch vehicles and launching a number of satellites (frequently piggy-backing small spacecraft on the launch of a larger one), weight was not actually a major consideration for the small satellite. With small. less costly launch vehicles, such as the Scout or Pegasus, weight and volume become much more important.
ITSAT provides the satellite designer with an option that will allow higher power for a given satellite need; or a lighter system with a smaller packaging volume for a given power need. More flexible packaging was an early goal which may not be realized in the near term. but is a possible goal for the long term.

\subsection{ITSAT Design Goals and Current Status}

\subsubsection{Power Densities for Systems}

During Phase 1 as part of the final design report. a summary curve of power densities for a variety of solar array systems was developed. Included on the curve was the ITSAT using crystalline silicon solar cells. Figure 1.3-1 presents this data. The curve clearly shows that the ITSAT can out-perform many of the state-of-the-art systems. While the nearest competitor is the Bi-Stem system, the ITSAT system at about 600 watts clearly has the advantage of higher power density.

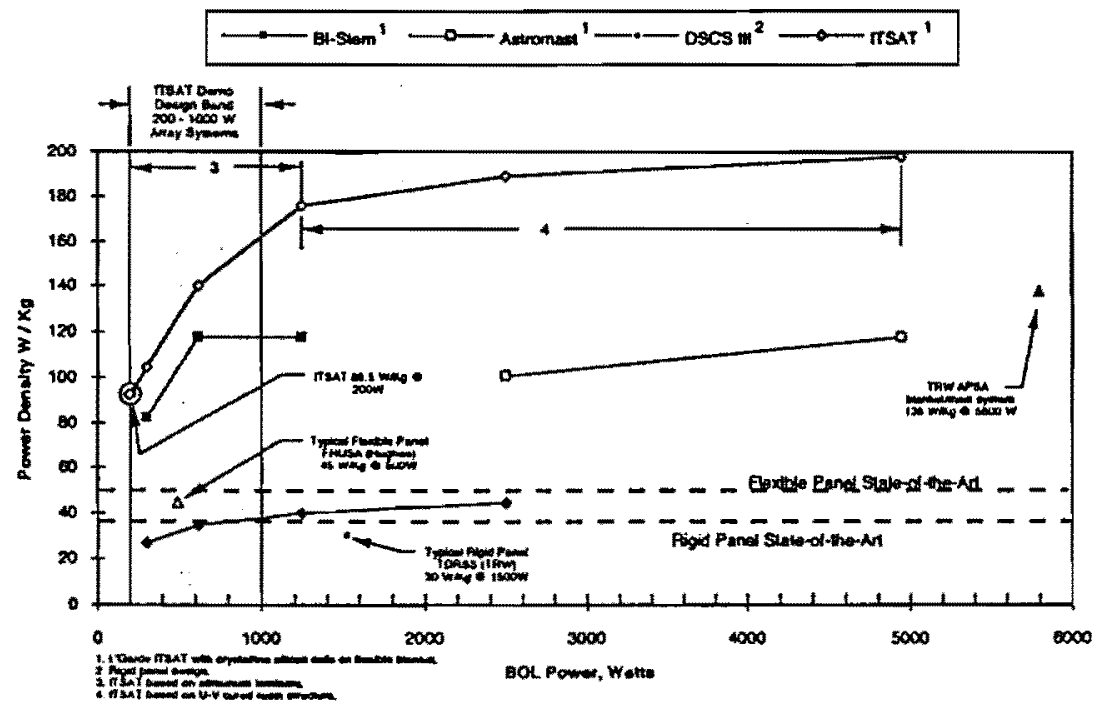

Figure 1.3-1. Deployment Comparison: ITSAT State-of-the-Art Arrays (80L/GEO/Crystal-Si)

\subsubsection{Status of Photovoltaic Types}

For the ITSAT Phase 1 prototype, several state-of-the-art solar cells were considered:

a) Thin crystalline silicon

b) Gallium arsenide on germanium

c) Cleft gallium arsenide

d) Copper indium diselenide

e) Amorphous silicon
(Cryst-Si)

(GaAs/Ge)

(Cleft GaAs)

(CIS)

(Asi)
Each type of cell has distinct advantages and disadvantages. For example, fabrication process for thin crystalline sillicon and GaAs/Ge cells are considered nore mature technologies. As such, the behaviors of these cells are well documented and predictable: their manufacture is relatively routine; there has been thorough radiation and other qualification testing: and they have been flown in space. Crystalline silicon, usually 8 to $12 \mathrm{mi}$ is thick, can now be etched to 2 mils to save weight. The overall thickness of GaAs, also $8 \mathrm{mils}$, has been reduced to $3.5 \mathrm{mils}$ for the same reason. However, the cells themselves are brittle. An array of them is flexible only in the 
sense that they can be attached to a flexible substrate that can be accordion-folded in such a way that the cells themselves are not creased.

Although amorphous silicon and CIS cells have the potential of being individually flexible (by deposition of the photovoltaic material directly on foils), their disadvantage is that the technology is less developed.

\subsection{ITSAT Design and Development}

\subsection{Phase 1 Effort}

\subsubsection{Point Design Summary}

Initially the ITSAT system was baselined using amorphous silicon solar cells under the assumption that the state-of-the-art would advance far enough (in approximately two to three years) that various array configurations could be designed and built.
Twelve point designs were investigated that would promise high power densities and some would require minimal pointing or no pointing at all. Additionally, later in the program several more designs were added for a total of seventeen point designs. A summary of these point designs is presented in Table 2.1-1 (Ref. 1).

The prototype configuration is shown in Figure 2.1.1-1. The flexible array was folded into 3 panels along the axis of the array then subsequently rolled up along the same axis. This required a flexible hinge capable of a "fold-and-roll" of the type found in Figure 2.1.1-2. This foldable design had the advantage of allowing the array to be packaged into a canister approximately $1 / 3$ the width of the array. However. during testing some anomalies were uncovered.

\begin{tabular}{|c|c|c|c|c|c|}
\hline $\begin{array}{l}\text { Point Design } 1 \\
\text { Point Design } 2 \\
\text { Point Design } 3 \\
\text { Point Design } 4 \\
\text { Design } 4 \text { Hod } \\
\text { Point Design } 5 \\
\text { Design } 5 \text { Hod } \\
\text { Point Design } 6 \\
\text { Point Design } 7 \\
\text { Design } 7 \text { Hod } \\
\text { Point Design } 8 \\
\text { Design } 8 \text { Mod } \\
\text { Point Design } 9 \\
\text { Point Design } 10 \\
\text { Point Design } 11 \\
\text { Point Design } 12 \\
\text { L'Garde extra. }\end{array}$ & $\begin{array}{l}\text { (extrap) } \\
\text { STEP } \\
\text { (extrap) } \\
\text { Techstars } \\
\text { (extrap) } \\
\text { STEp } \\
\text { (extrap) } \\
\text { Techstars }\end{array}$ & $\begin{array}{l}200 \text { watts } \\
200 \text { watts } \\
200 \text { watts } \\
200 \text { watts } \\
200 \text { watts } \\
200 \text { watts } \\
200 \text { watts } \\
200 \text { watts } \\
200 \text { watts } \\
200 \text { watts } \\
200 \text { watts } \\
200 \text { watts } \\
200 \text { watts } \\
1000 \text { watts } \\
2500 \text { watts } \\
5000 \text { watts } \\
1000 \text { watts }\end{array}$ & $\begin{array}{l}\text { Spherical } \\
\text { Pillow } \\
\text { Tubular } \\
\text { Spherical } \\
\text { Tubular } \\
\text { Pillow } \\
\text { Tubular } \\
\text { Tubular } \\
\text { Spherical } \\
\text { Tubular } \\
\text { Pillow } \\
\text { Tubular } \\
\text { Tubular } \\
\text { Tubular } \\
\text { Tubular } \\
\text { Tubular } \\
\text { Tubular }\end{array}$ & $\begin{array}{l}740 \mathrm{~km} \text { polar (LEO) } \\
740 \mathrm{~km} \text { polar(LEO) } \\
740 \mathrm{~km} \text { polar(LEO) } \\
6 \text { hour Molniya } \\
6 \text { hour Molniya } \\
6 \text { hour Molniya } \\
6 \text { hour Molniya } \\
6 \text { hour Holniya } \\
\text { GEO } \\
6 E O \\
\text { GEO } \\
\text { GEO } \\
\text { GEO } \\
\text { lOOOOkm, } 60^{\circ} \\
3000 \mathrm{~km}, 0^{\circ} \\
\text { LEO-GEO transfer } \\
\text { LEO/GEO }\end{array}$ & $\begin{array}{l}3 \text { year } \\
3 \text { year } \\
3 \text { year } \\
3 \text { year } \\
3 \text { year } \\
3 \text { year } \\
3 \text { year } \\
3 \text { year } \\
3 \text { year } \\
3 \text { year } \\
3 \text { year } \\
3 \text { year } \\
3 \text { year } \\
1 \text { year } \\
1 \text { year } \\
1 \text { year } \\
3 \text { year }\end{array}$ \\
\hline
\end{tabular}

Table 2.1-1. Point Design Summary

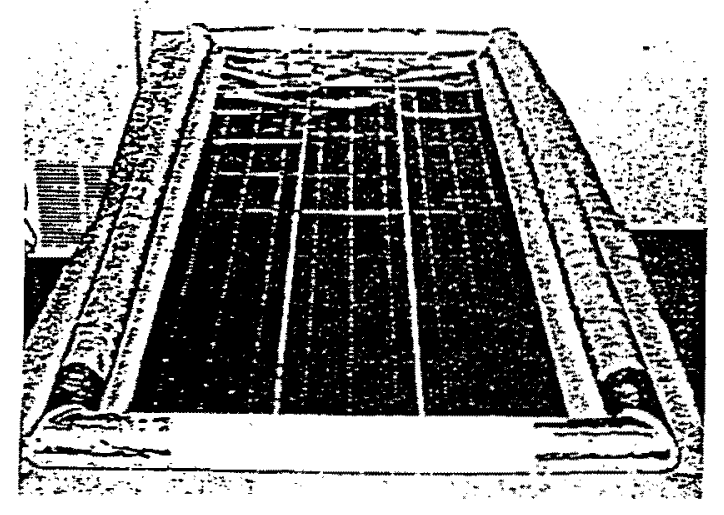

Figure 2.1.1-1. Prototype Unit 


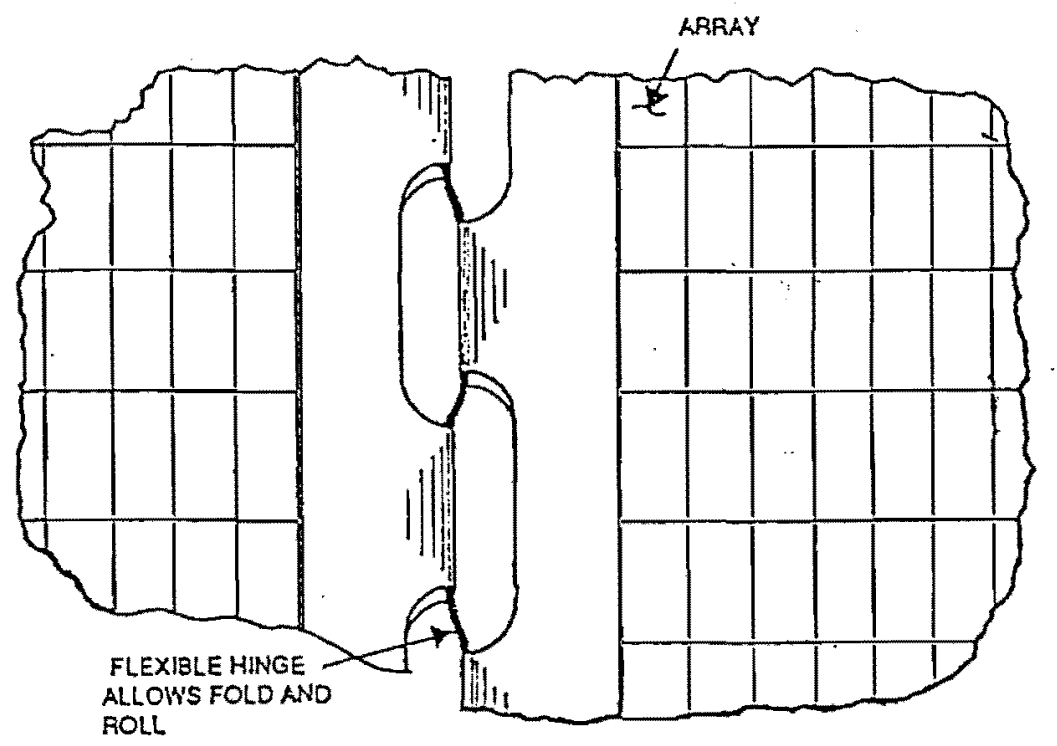

Figure 2.1.1-2. Array Hinge Design

First, this concept required a four-sided torus with corner joints. The stress in the corner joints exceeded that of the material. and necessitated additional stiffening layers of the 1 aminate. While the now stronger torus was able to handle the pressure, the material thickness had grown to the point of being inflexible: it was impossible to package into the canister volume. negating one of the primary advantages of inflatables - their ability to be packaged into small conformal volumes.

The second problem was that of unfolding the torus in a repeatable, reliable manner. Too many degrees of freedom for the unfolding torus lead to a possible over-stress situation for the solar blanket.

The three most important lessons learned from phase I were: 1) The material thickness must be kept to a minimum to enhance packagability (not to mention weight limitations); 2) A sharp 90 degree corner joint is undesirable due the stress concentration; and 3) The simpler the torus, the better.

\subsubsection{Current Desian}

Parallel to the phase I design effort. other cell technologies were carefully investigated. While there exist several advanced cell technologies with higher efficiencies, none is so well developed or as inexpensive as crystalline silicon. The latter has been used on almost every solar panel satellite since the beginning of the space program and possesses a very large knowledge base to draw from.

\section{New Array Technolocy}

A new technology developed by TRW on their Advanced Photovotaic Solar Array Program (APSA) gives an alternative to the amorphous silicon arrays (Ref. 2). Standard Silicon cells are bonded to a blanket of $2 \mathrm{mil}$ Kapton and interconnected in the usual manner. A flat flexible wiring harness, very similar to that used on computer printers and plotters, is used to route the power from the cell strings to the satellite bus. To allow a large panel to fit into a small volume requires the blanket be folded accordion style, perpendicular to the deployment direction. And while the compound fold used in phase 1 allows packaging into a narrower canister. it was abandoned in this design in favor of the simpler unidirectional fold. As with other test panels, a full population is deemed unnecessary. To establish continuity of the cell strings after deployment, only a $10 \%$ population is to be used.

This return to a "tried and true" Crystalline silicon cell technology solves the problem of a constantly degrading cell such as amorphous silicon; the problem becomes one of incorporating a semi-flexible blanket into a configuration originally designed for completely flexible arrays.

\section{Hechanical Design}

The new design is shown pictorially in Figure 2.2.2-1. The corner joints are not used in this design by simply letting the canister and its iid perform as two of the sides of the torus. In fact, the word "torus" as it was originally defined in the first phase, may now be more aptly described as two parallel booms. The blanket is to be attached to the booms in several places along its length, by cables going from gromets in the blanket to straps that wrap around the boons. From experience gained on phase 1 , the deployment shown in the figure is accurately depicted with respect to the folds in the booms. This method limits out-of-plane motion of the inflating boom. 


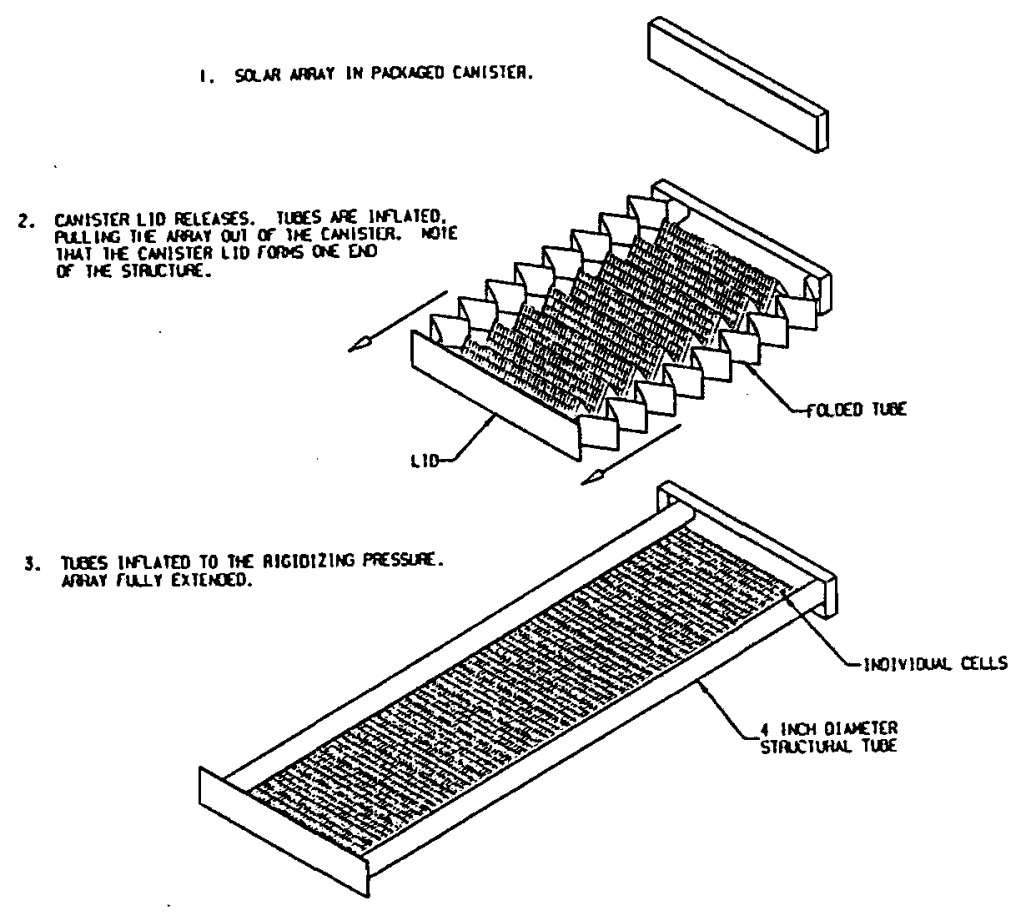

Figure 2.2.2-1. ITSAT PH2 Design

The tubes are permanently rigidized by inflation pressure to eliminate the need for make-up gas, the weight of which becomes very high for this relatively long mission (three years) in the harsh meteoroid environment of LEO. Dry nitrogen inflatant fills the booms to a pressure that removes all the packaging wrinkles and causes the material to stress to its yield point to become permanently smooth. At this point. it does not matter if the inflatant leaks out or not since the extremely thin but strong monocoque cylinder is in place. From tests on 24 inch long sample tubes. the required inflation pressure turns out to be 22 psi on the 4 inch diameter tube. More on the materials aspect will be given in Section 2.2.3.
The inflation system is shown in Figure 2.2.2-2. A custom-made tank was required to fit in the low profile canister. Upon command from the controller unit, a pyrotechnic puncture cutter will pierce an aluminum diaphragm to let the gas flow from the tank. There it will flow through the primary restrictor which allows only a very slow flow rate. This restriction is necessary to assure that the blanket deploys slowly and, therefore, safely. The last component of the inflation valve assembly is a vent valve, which allows any trapped air in the packaged booms to vent during ascent in the launch vehicle; thereby avoiding premature inflation. Prior to releasing the gas, the vent is open to atmosphere. Upon release the vent will close due to the pressure of the gas.

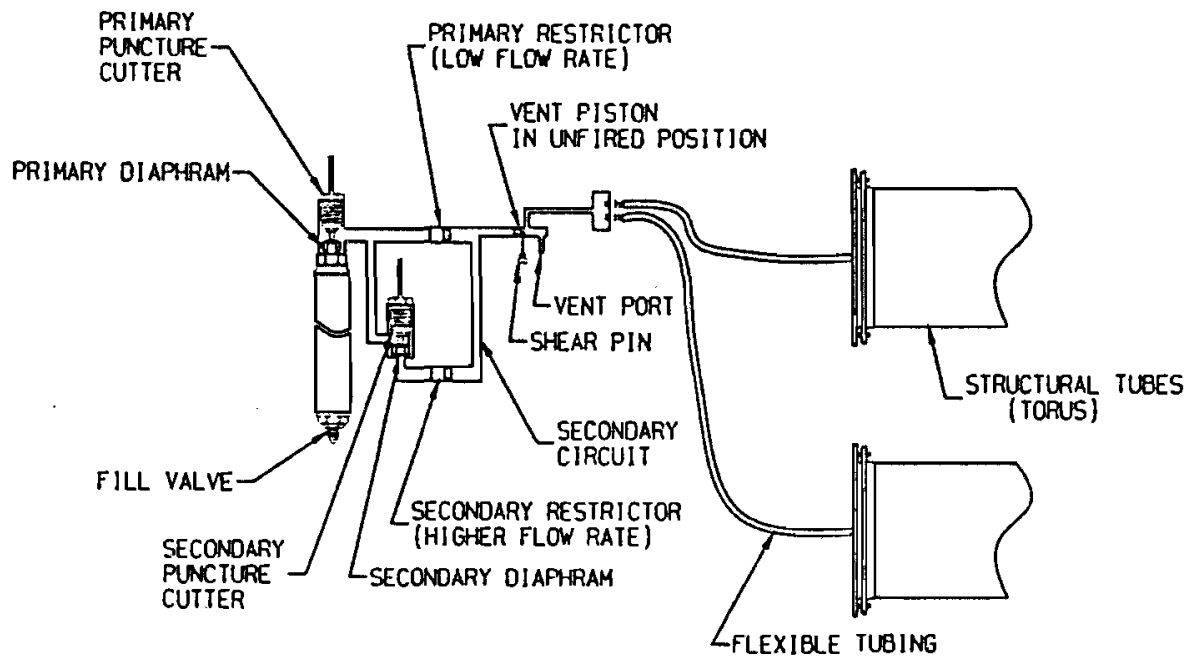

Figure 2.2.2-2. Inflation System Schematic 
If the inflation system used the primary circuit only. inflation would take much longer than necessary. As the gas flows from the tank, the tank pressure drops, reducing the flow rate further. To avoid the tubes remaining in the unrigidized state for a long period, a secondary circuit is used. Like the primary, it has a puncture cutter to start the flow through a parallel path. However, its restrictor is sized to allow a much faster flow rate which is safe now that the tubes are extended. After the restrictor. the gas flows through the vent valve, which has already been opened during the primary inflation sequence.

Our tests indicate an inflation time of one minute. The actual inflation system and tank is shown in Figure 2.2.2-3.
The light-weight budget dictated a composite housing and lid. Most of the housing consists of $1 / 8$ inch and $1 / 2$ inch thick Nomex honeycomb with 5 mil thick graphite-epoxy facesheets bonded to both sides. Reinforcements are used on all corner joints. The lid is constructed similarly, with a small flange overhanging all four edges. The latch mechanism for the lid consists of a pyrotechnic cable cutter. cutting a small cable that holds down the lid. Ejector springs are unnecessary for the lid since the boons will cause separation when inflated.

The development test unit is shown in Figure 2.2.2-4. The inflation system is mounted on the back of the housing. The ITSAT assembly mounts to the host spacecraft with 4 bolts at the center of the housing.

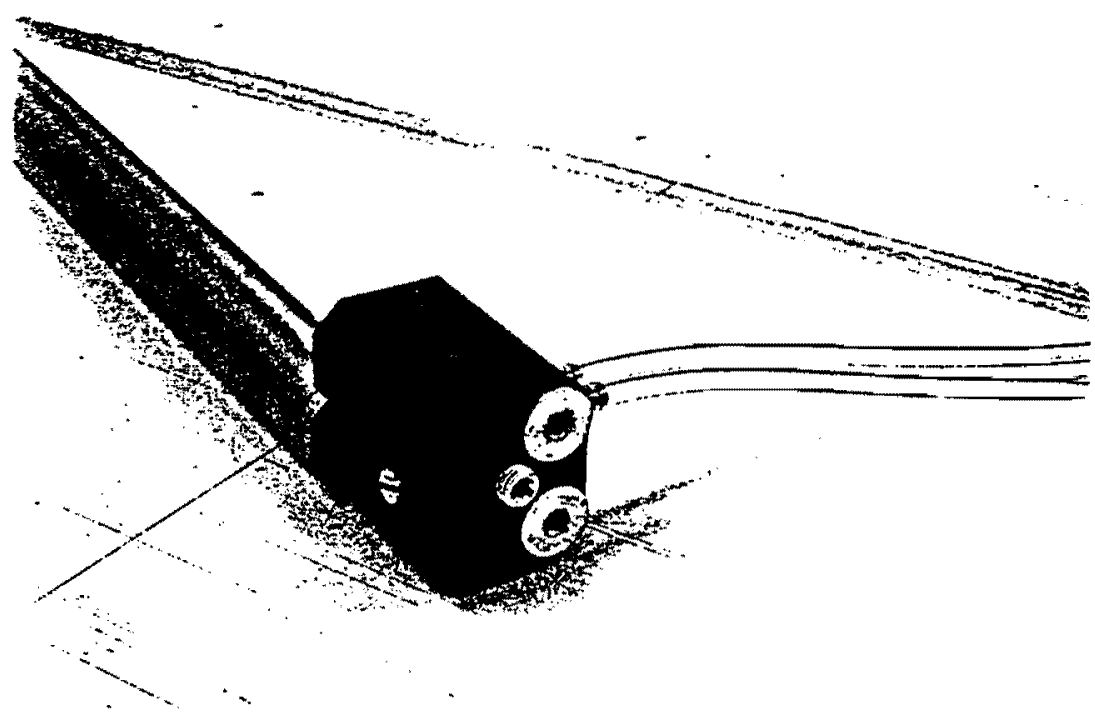

Figure 2.2.2-3. Inflation System with Tank

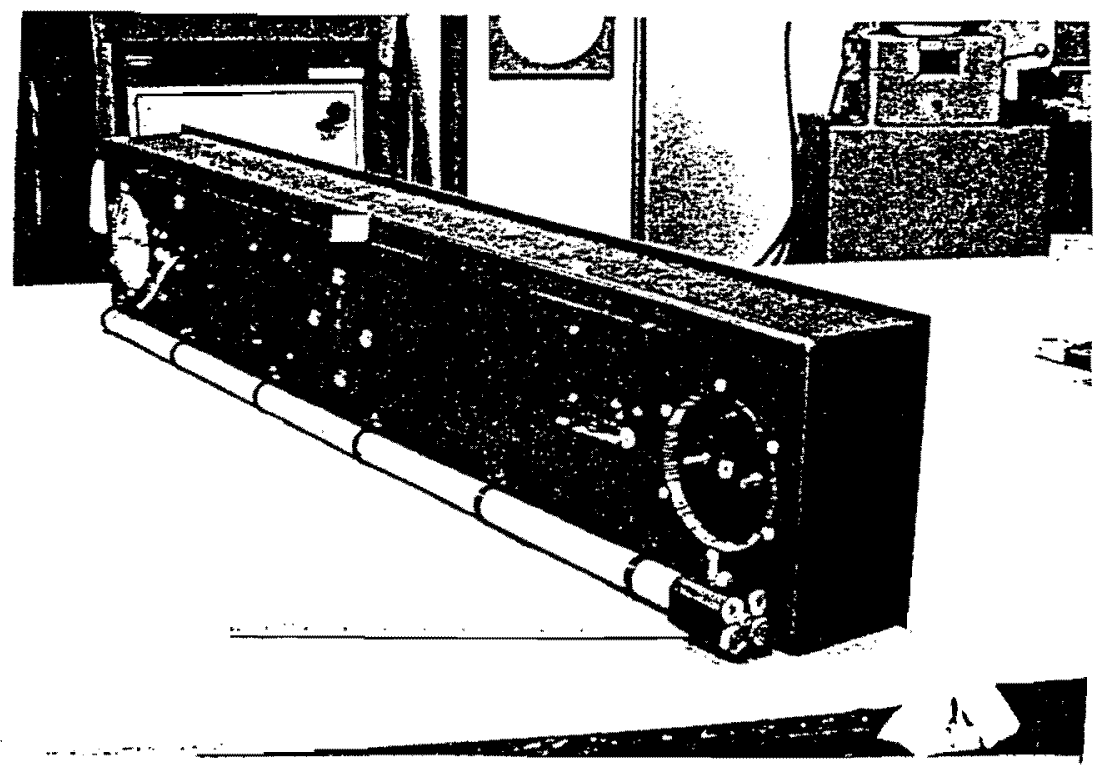

Figure 2.2.2-4. Development Test Unit 
The booms running along each side of the array becane a development effort in itself. The laminate is aluminum foil sandwiched between two layers of thin plastic. The plastic film is necessary to hold the pressure when inflating by increasing the tear resistance; otherwise the soft foldable aluminum would tear very easily. allowing large leak paths. Numerous laminate combinations were fabricated and tested in phase I. including three different alloys of al uminum $(5052-0.1145-0$. and $3003-0)$, and several varieties of reinforced and non-reinforced plastic. During phase II. differences between reinforced and non-reinforced plastic films were re-examined more closely. of particular concern. is that all materials be space-qualified against the moderately harsh environment of Atomic Oxygen (AO) and other factors.
The final laminate selection turned out to be 3 mil 3003-0 aluminum between two layers of reinforced $1 / 2$ mil Kapton. The full length tube is shown in Figure 2.2.3-1. The reinforcement in the Kapton is made of $16 \times 16$ yarn/inch of 140 denier nylon yarn. The adhesive selected for making the seams is silicon-based and space-qualified made by Dow Corning (DC 6-1125) due to its previous space environment qualification. The coating selected for the Kapton is Indium-Tin-0xide (ITO), selected not only for its $A O$ resistance. but also for a surface conductivity which is sufficient to prevent static discharge. If minor cracks occur in the coating, they are of minimal concern since the booms are not intended to hold pressure for the duration of the mission; the AO protection is there rather to prevent large chips from peeling and landing on top of active solar cells.

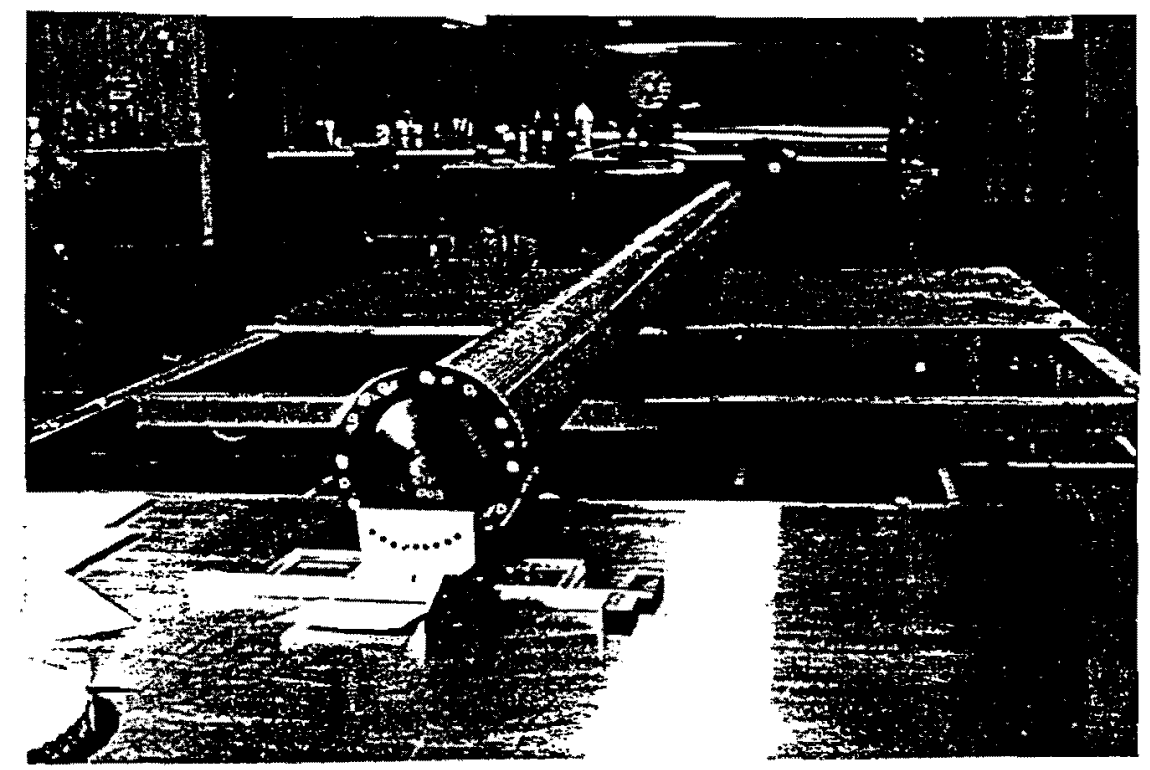

Figure 2.2.3-1. Flight Tube

\subsubsection{Array Blanket}

The lightweight blanket uses 2 mil Kapton as the substrate. The overall view is shown in Figure 2.2.4-1. The blanket is populated by a number of devices:

8 mil Silicon Solar Cells - 6 rows

2 mil Silicon Solar Cells - 1 row

6 mil Glass Simulators

6 mil Two-Ply Giass Simulators (two 2.5 mil glasses bonded together)

6 mil Aluminum Simulators
In addition. resistance temperature devices (RTO's) are mounted on the back of the working cells to monitor cell temperature. Bypass diodes are incorporated to allow for damaged cells and partial shading.

Thermal cycling of the blanket was a concern. To test the strength of the cell-tosubstrate bond and the coverglass bonding, a sample of the solar blanket was sent to NASA-Lewis for rapid thermal cycling (Figure 2.2.4-2). No physical damage nor degradation occurred during the test (Ref. 3). This coupon was cycled from $-100^{\circ} \mathrm{C}$ to $+80^{\circ} \mathrm{C}$ for a total of 2000 cycles. 


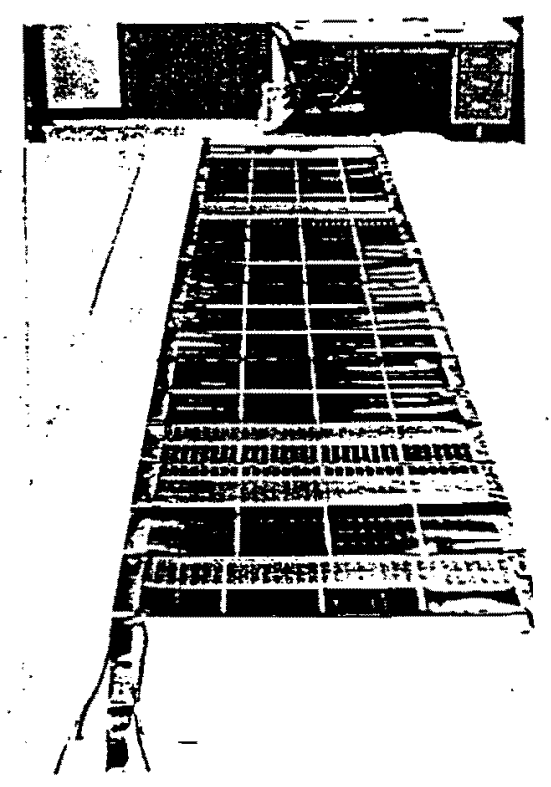

Figure 2,2.4-1. Array Blanket - Overall View

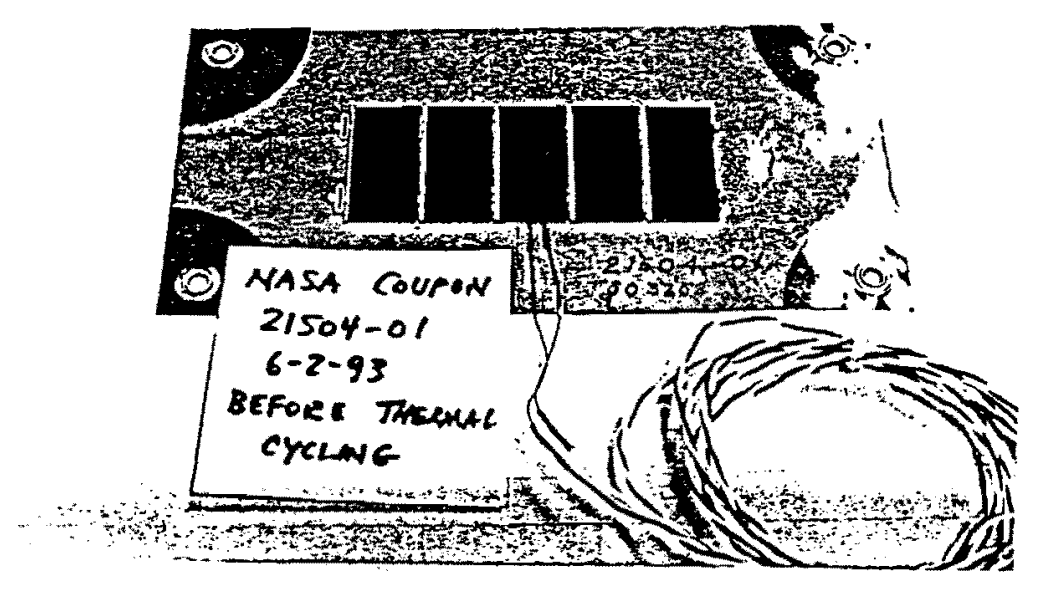

Figure 2.2.4-2. Sample Solar Blanket

\subsubsection{Current Performance Predictions}

In summary, the performance of the ITSAT design is shown in Figure 2.2.5-1. Our current engineering protoflight unit uses proven inflation components (i.e. traditional cold gas inflation. previously tested 4 inch diameter tube struts and previously flown ordnance initiators). a $10 \%$ population of $8 \mathrm{mil}$ cells and a single string of 2 mil cells, with the balance of the cells made up of 2 mil cell simulators. The specific power is calculated at $65 \mathrm{BOL} \mathrm{W/kg}$ at an array output of 274 BOL watts.
By further optimizing the tubes, enclosure, inflation systen, other components and aspect ratio, it is possible to easily increase the specific power to $86 \mathrm{~W} / \mathrm{kg}$. still using crystalline silicon solar cells. Specific powers above $90 \mathrm{~W} / \mathrm{kg}$ can be realized if non-traditional inflation system components such as sodium-azide are used. Additionally, advanced technology solar cells like cleft GaAs will increase the specific power further. Another advantage of the ITSAT design is this adaptability to a variety of cell types. 


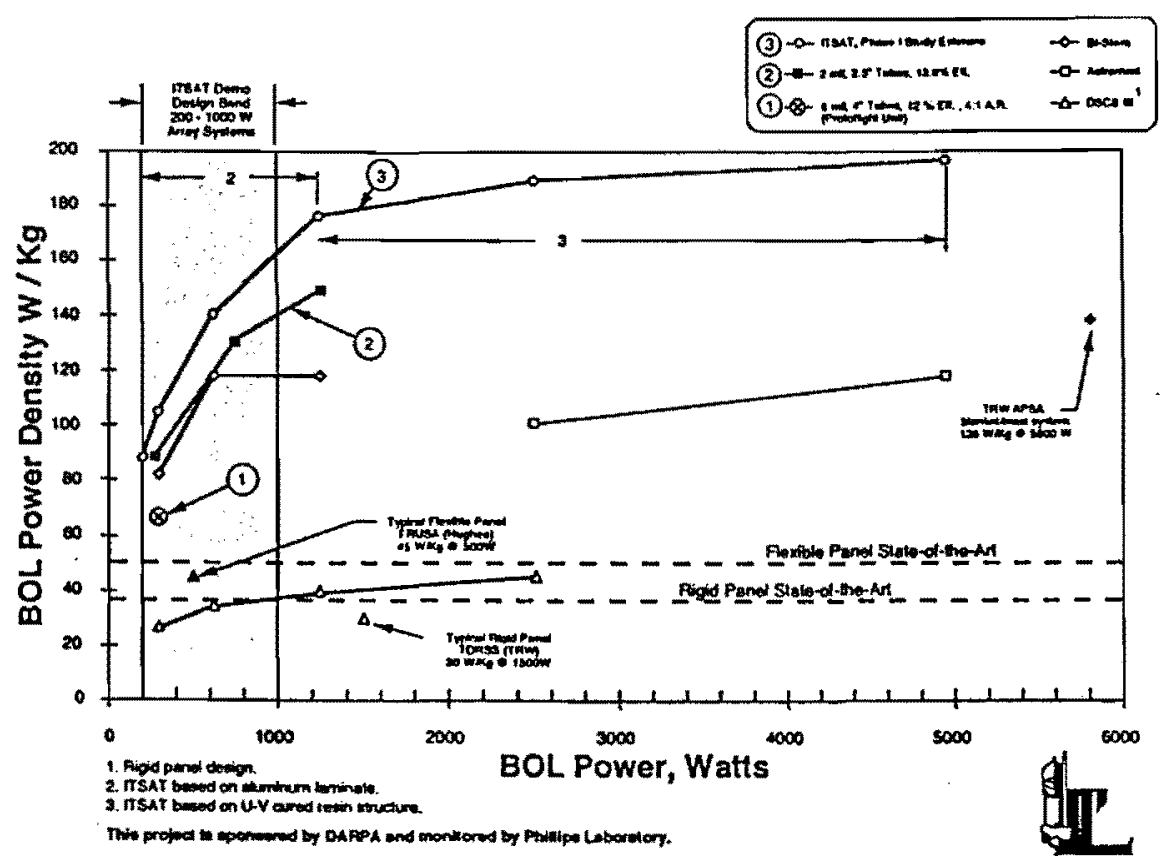

Figure 2.2.5-1. ITSAT Design Performance Sumary

\subsection{Flight Test}

The plan has been to test a flight-qualified array system in space for a minimum of one year, and to continue the test past the one year period up to three years. A ride will be sought on a free-flying spacecraft. There is a high probability that the flight will be on a small spacecraft, such as a STEP spacecraft and launch vehicles will be considered if available.

To reduce costs, we will use one array for both qualification and flight testing. This system is partially populated with active cells and the remainder by simulated cells. To qualify the system for flight, one-of-a-kind spacecraft methodology is employed.

The deployment in space will be observed with a small video camera mounted on the host spacecraft. Periodic $1-V$ data $w 111$ be gathered. evaluated and compared to solar array output and temperatures from the host spacecraft.

\subsubsection{Flight Qualification}

The combination of low budget and a unique design not previously flight-tested creates problems in qualifying the subsystem for space flight. The concept design which was built and tested for Phase 1 was a complete torus of four integral inflated and rigidized sides. Two approaches to qualification were considered, each requiring a number of toruses (or Tori) for test:

1. Construct two, three or, four toruses, packaged as if for launch; deploy in the laboratory; repeat a number of times. If repackaging and re-deployment is found feasible. then the flight model can go through acceptance test deployment and be repackaged for flight. This method has the risk that repeated folding of tubes have resulted in the sharp bends of the aluminum making holes in the plastic layers. The resulting holes leak gas, so that full inflation might not be possible with the limited gas supply carried aboard.

2. Construct, fold, and deploy a number of tubes (and possibly a number of corner constructions so as to produce a statistical prediction of the reliability of deployment. The flight torus would be folded, packaged. launched. and deployed without a prior deployment test on the ground.

The approach being considered for phase II is that used for many one time operation devices, e.g. primary batteries, pyrotechnic devices, solid rocket motors, etc. The modified design, using the enclosure and cover holding the folded array for he two ends of the torus and two inflatable then rigidized booms as the sides of the torus, adapts to the second approach for qualifying the device. A number of tubes will be built and tested for deployment reliability. The flight array system can be fully tested including deployment test, then the two sides boons removed and replaced with new ones for launch.

Qualification and acceptance testing standards are described in MIL-STO 1540B (USAF) Test Requirements for Space Vehicles. These are further defined and provisions made for flying the qualification test article in DOD-HDBK-343 "Design. Construction, and Testing Requirements for One-of-a-Kind Space Equipment". HDBK-343 recognizes four classes of programs, A, B, C, and $D$; the class of a particular program depending on importance of mission or national prestige, risk, cost of project, cost of fallure, etc. For one of a kind components, the testing requirements are:

Class $A$ requires a test article to be flown by being subjected to "protoflight tests" which are intermediate to the class $A$ qualification tests and the acceptance tests. e.g.. the test article is to be tested over the design range of temperatures: for class $A$ and $B$ the design range is $10^{\circ} \mathrm{C}$ beyond 
the maximum and minimum predicted temperatures: for class 8 protoflight tests the design range is $5^{\circ} \mathrm{C}$ beyond the maximum and minimum predicted temperatures.

Class $C$ and $D$ relaxes the tests still further, e.g.. the design temperature range is the maximun and minimum predicted temperatures.

Ve will test the ITSAT to class B or higher levels.

\subsection{Summary and Conclusion}

The ITSAT system advances the state-ofthe-art by providing power densities greater than many current technologies by using traditional inflation methods. Figure 2.2.5-1 presented in Section 2.2.5 is a comparison of many recent solar array systems in comparison to the ITSAT technologies. The ITSAT surpasses even the Bi-stem system at power levels above 600 watts.

In conclusion, the ITSAT system has shown its feasibility during the Phase I effort and is now being qualified for flight. The flight system will be available for integration with a sponsored satellite some time in late 1994.

\section{Acknowledgenents}

This work has been funded by the Advanced Projects Research Agency and monitored by USAF Phillips Laboratory. The authors wish to express their thanks to Dr. Costa Cassapakis, L'Garde, Inc. and $\mathrm{Dr}$. Frank Jankowski, USAF/PL, retired for their many helpful suggestions. Additionally, we wish to thank Dr. George Vendura, Jr.. SUMM Associates for his contributions in the areas of solar cell technology and solar cell performance. This paper is a revised version of papers. presented at the NASA/DoD Flight Experimenters Technical Interchange Meeting, Monterey, Cali fornia, October 1992 and the 1993 Space Power Workshop, Albuquerque, New Hexico, April 1993.

\section{References}

1. Veal, G.. "Inflatable Torus Solar Array Technology Program - Final Report", L'Garde Technical Report LTR-91-GV-022, Contract \#F29601-90-C-0006, December 1991.

2. Kurland, R.. "Advanced Photovoltaic Solar Array Prototype Development Testing" " TRW Report 151760-6005-UT-00, JPL Contract 957990 (Mod 10). August 12, 1991 .

3. Williams, G. and Davey, K.. "Thermal Cycling of NASA Coupon", L'Garde Technical Report ILTR-93GTW-036, June 1993. 